\title{
PENGARUH KOMUNIKASI INTERPERSONAL DAN DISIPLIN TERHADAP PRODUKTIVITAS PENGAWAS DI DINAS PENDIDIKAN KABUPATEN BEKASI
}

\author{
Yuliana*
}

\begin{abstract}
The objective of this research was to determine the direct effect of interpersonal communication and discipline on supervisor productivity. The study was conducted at Education Department Bekasi Regency. The research was conducted using survey method with qualitatif approach an path analysis technique. Based on the result of data analysis in this research it is concluded: (1)the interpersonal communication have positive direct effect to productivity, (2)the discipline have positif direct effect to productivity, (3)the interpersonal communicaton have positive direct effect to discipline. The supervisor productivity can be improved by improvement the interpersonal communication and discipline.
\end{abstract}

\section{Keywords: Productivity, Interpersonal Communication, and Discipline}

\section{PENDAHULUAN}

Memasuki era globalisasi dengan perdagangan bebas diperlukan sumber daya yang berkualitas. Pendidikan merupakan salah satu cara untuk meningkatkan sumber daya manusia yang. Berbagai upaya sudah dilakukan pemerintah misalnya pengembangan kurikulum (KTSP), peningkatan kompetensi pendidik dan tenaga pendidikan melalui berbagai pelatihan, pengadaan buku dan fasilitas pembelajaran, pengadaan sarana dan prasarana serta peningkatan mutu manajemen pendidikan di sekolah. Namun demikian, mutu pendidikan belum menunjukan peningkatan yang diharapkan.

Penyelenggaraan pendidikan sekolah melibatkan tanggung jawab pengelola pendidikan yaitu Dinas Pendidikan yang bertugas sebagai penanggung jawab program pendidikan dan pengawas sekolah yang bertugas melakukan pengawasan. Tugas pokok pengawas sekolah adalah melaksanakan pengawasan akademik dan pengawasan manajerial pada satuan pendidikan. Hal Ini menandakan pengawas sekolah bertanggung jawab dalam peningkatan mutu pendidikan dan sebagai penjamin mutu pendidikan di sekolah yang dibinanya (termasuk kualitas guru dan kepala sekolah).

Kenyataan yang terjadi kualitas guru masih kurang, berdasarkan hasil Uji Kompetensi Awal (UKA) 2012 hasil rerata hanya 47,84. Bahkan dari 281.016 peserta UKA, sebanyak 606 peserta pengawas memiliki rerata ujian paling rendah yaitu 32,58 lebih kecil dari rerata guru yang dibinanya. Pengawas harus memiliki kompetensi kepribadian, kompetensi sosial, kompetensi supervisi manajerial, kompetensi supervisi akademik, kompetensi evaluasi pendidikan dan kompetensi penelitian dan pengembangan. Peranan pengawas sepertinya belum maksimal sebagai penjamin mutu sekolah binaannya.

Dalam menjalankan tugas dan tanggung jawabnya diperlukan suatu perilaku kerja dengan produktivitas yang tinggi yang didalamnya sudah terangkum motivasi, kemampuan, keinginan yang besar untuk meningkatkan mutu pendidikan minimal sekolah binaannya. Berdasarkan informasi dari beberapa guru di Kabupaten Bekasi terdapat beberapa kesalahan persepsi guru mengenai tugas dan tanggung jawab pengawas. Guru cenderung menilai pengawas datang hanya untuk bertamu ke sekolah,

\footnotetext{
* Guru SMA Negeri 1 Serang Baru Kabupaten Bekasi
} 
bukan untuk pembinaan. Kalaupun ada pengawas yang hendak supervisi kelas, masih ada guru yang enggan untuk disupervisi. Di beberapa sekolah ada juga pengawas yang datang hanya satu atau dua kali saja atau datang ketika ada kegiatan sekolah seperti Akreditasi, Ulangan Akhir Semester (UAS), Ulangan Kenaikan Kelas (UKK), Ujian Sekolah dan Ujian Nasional.

Hal ini mungkin dikarenakan adanya kurangnya penyampaian informasi/komunikasi mengenai maksud dan tujuan supervisi dari pengawas kepada guru, kurang intensifnya pengawas dalam melakukan pembinaan terhadap guru/kepala sekolah sehingga komunikasi interpersonal yang terjalin rendah. Berbagai permasalahan yang terjadi menandakan produktivitas pengawas masih rendah disebabkan oleh beberapa faktor diantaranya diantaranya disiplin yang masih rendah dan dikarenakan rendahnya kemampuan berkomunikasi interpersonal yang dimiliki pengawas dalam berinteraksi dengan guru atau kepala sekolah. Betapa besar fungsi dan tugas pengawas sebagai salah satu penunjang mutu pendidikan, maka penelitian ini penting untuk dilakukan untuk mengkaji mengenai bagaimana pengaruh faktor disiplin dan komunikasi interpersonal terhadap produktivitas pengawas.

\section{Produktivitas}

Bernadin dan Russel (1993:518) mendefinisikan produktivitas sebagai "productivity can be defined in a variety of ways by an organization, depending on its goal (e.g profit s, customer satisfaction)" (Produktivitas dapat didefinisikan dalam berbagai cara oleh sebuah organisasi tergantung pada tujuannya (misalnya keuntungan, kepuasan pelanggan)). Jay Heizer dan Barry Render (2009:14) mengemukakan bahwa " productivity is the ratio of outputs (goods and services) divided by the inputs (resources, such as labor and capital)" (Produktivitas adalah rasio output (barang dan jasa) dibagi dengan input (sumber daya seperti tenaga kerja dan modal)).

Sedangkan Heiz dan Harold (2005:10) menjabarkan "productivity is the outputinput ratio within a time period with due consideration for quality" (Produktivitas sebagai ratio antara ouput dan input dalam periode tertentu dengan mempertimbangkan kualitas). Jadi produktivitas tidak hanya dilihat dari jumlah output yang tinggi saja tetapi juga dari penggunaan waktu dalam menghasilkan output tersebut. Warren dan Jerome (1993: 116) mendefinisikan juga bahwa "productivity is ratio of output produced to inputs required (an expected outcome of total quality)" (Produktivitas sebagai rasio antara output dan input suatu proses produksi dalam periode tertentu (sebagai hasil dari mutu terpadu)). Konsep di atas lebih dalam lagi bahwa output yang dihasilkan dengan periode tertentu merupakan output yang berkualitas.

Robbins dan Coulter (2009:299) mendefinisikan "employee productivity is a performance measure of both efficiency and effectiveness" (produktivitas pekerja adalah ukuran kinerja dari efektivitas dan efisiensi). Griffin (2007: 668) juga mengemukakan bahwa "productivity is an economic measure of efficiency that summarizes the value of output relative to the value of inputs used to create then"(Produktivitas adalah ukuran ekonomi efisiensi yang merangkum nilai output relatif terhadap nilai input yang kemudian digunakan untuk diciptakan).

Certo (2010:50) juga mengemukakan produktivitas meningkat ketika organisasi dapat meningkatkan pekerjaan dengan biaya yang lebih rendah dan output meningkat tanpa adanya peningkatan biaya. Cara lain untuk meningkatkan produktivitas adalah meningkatkan kualitas proses sehingga pegawai bekerja lebih efisien dan tidak harus menghabiskan waktu untuk mengoreksi kesalahan atau cacat. Dengan beberapa cara di 
atas Certo (2010:50) menyimpulkan supervisor dapat meningkatkan produktivitas mereka sendiri dan tim mereka atau kelompok dengan memahami tujuan program kualitas dan peran mereka sendiri dalam mencapai tujuan-tujuan.

Berdasarkan pemaparan di atas dapat disintesiskan bahwa produktivitas adalah perilaku seseorang dalam menggunakan sumber daya yang berkualitas pada proses pencapaian tujuan organisasi untuk hasil yang berkualitas secara efektif dan efisien.

\section{Komunikasi Interpersonal}

Newstrom(2007:45) mendefinisikan bahwa "communication is the transfer of information and understanding from one person to an other person" (Komunikasi merupakan suatu proses pemindahan informasi dan pemahaman dari seseorang kepada orang lain). Debra L. Nelson (2006:250) mengemukakan tentang komunikasi bahwa "communication is the evoking of a shared or common meaning in another person" (Komunikasi adalah membangun makna bersama dengan orang lain).

Robert P. Vecchio (2006:294) mendefinisikan "communication the exchange of messages between persons for the purpose of a mental image in the mind of a receiver in exacthy the same detail as intended by the sender" (Komunikasi merupakan pertukaran pesan diantara orang-orang dengan tujuan menyamakan arti pesan). Rue dan Byars (2010:41) menjelaskan bahwa "interpersonel communication is an interactive process between individuals that involves sending and receiving verbal and nonverbal messages" (Komunikasi interpersonal adalah proses interaktif antara individu yang melibatkan pengirim dan penerima pesan verbal dan nonverbal).

Judy C. Pearson (2008:316) berpendapat bahwa komunikasi interpersonal didefinisikan sebagai proses menggunakan pesan untuk menghasilkan makna antara setidaknya dua orang dalam situasi yang memungkinkan peluang untuk kedua saling berbicara dan mendengarkan. De Vito (2007:5) mengemukakan bahwa komunikasi interpersonal adalah komunikasi yang terjadi antara dua orang yang memiliki hubungan yang dibangun orang-orang dalam beberapa cara "terhubung" komunikasi interpersonal akan hal ini termasuk apa yang terjadi antara seorang anak dan ayahnya, majikan dan pegawai, dua saudara perempuan, yang guru dan murid, dua kekasih, dua teman dan sebagainya.

Von Glinov (2008:327) mengemukakan bahwa komunikasi interpersonal yang efektif tergantung pada sisi kepentingan dan kemampuan memperoleh pesan secara terus menerus. Dua keistimewaan yang menyangkut Komunikasi interpersonal menampung pesan dan mendengarkannya. Manusia belajar menjadi manusia melalui komunikasi, kepribadiannya terbentuk melalui komunikasi, bagaimamana ia menafsirkan pesan yang diperolehnya dan bagaimana ia menyampaikan pesannya kepada orang lain, jadi manusia tidak terbentuk hanya dengan lingkungannya saja.

Debra L. Nelson (2006:250) mengemukakan bahwa "interpersonal communication is occurs between two or more people in an organization" ( Komunikasi interpersonal adalah komunikasi yang terjadi antara dua orang atau lebih dalam organisasi). Lebih lanjut Debra L Nelson mengatakan komunikasi interpersonal adalah penting dalam membangun dan mempertahankan hubungan manusia ditempat kerja. Nelson dan Quick (2006:251) dalam bukunya Organizational behavior: Foundation, Realities $\mathcal{E}$ Challenges menggambarkan unsur-unsur kunci dari komunikasi interpersonal adalah komunikator, penerima, persepsi dan pesan.

Berdasarkan deskripsi konseptual di atas dapat disintesakan komunikasi interpersonal adalah interaksi dua orang atau lebih yang memiliki tujuan untuk 
menghasilkan makna, dengan indikator: proses penyampaian pesan, timbal balik, hubungan yang produktif dan persepsi (makna) yang sama.

\section{Disiplin}

Menurut Certo (2010:326) "discipline is action taken by a supervisor to prevent employees from breaking rules. In many cases effective discipline can quickly bring about a change in an employee's behavior"(disiplin adalah tindakan yang dilakukan oleh supervisor untuk mencegah pegawai melanggar aturan. Dalam banyak kasus disiplin efektif dengan cepat dapat membawa perubahan dalam perilaku pegawai).

Hersey (1995:210) juga mengemukakan hal itu dikarenakan disiplin sering dipandang sebagai intervensi negatif. Tapi disiplin kata aslinya adalah "pengikut", pengikut yang lebih sempit. Sayangnya dalam budaya kita banyak orang menafsirkan disiplin sebagai hukuman. Tapi itu tidak selalu harus dihukum. Pemecahan masalah sifat disiplin Konstruktif membedakan disiplin dan hukuman. Sebagai disiplin Konstruktif tersebut dirancang untuk menjadi sebuah proses pembelajaran yang memberikan opprtunity untuk pertumbuhan positif.

Greenberg (2009:67) mengemukakan bahwa "discipline is the process of systematically administering punishment" (disiplin adalah proses sistematis pemberian hukuman). Jadi disiplin itu bukan suatu hukuman yang tiba-tiba tetapi ada proses yang sistematis di dalamnya. Luthan (2008:308) mengemukakan dalam kaitan pemberian sanksi terhadap suatu pelanggaran disiplin, maka perlu (a) segera dilaksanakan sanksi sedini mungkin (b) diadakan pengamatan terhadap pelanggaran yang dilakukan (c) berlaku adil dalam penerapan sanksi (d) kontinuitas dalam penerapan sanksi (e) setiap sanksi harus bersifat memberi dorongan ke arah perbaikan selanjutnya dari si pelanggar.

Bacal (1999:135) mengemukakan definisi disiplin sebagai proses yang digunakan untuk mengatasi masalah kinerja, melibatkan manajer dalam mengidentifikasi dan mengkomunikasikan masalah kinerja kepada pegawai dan dalam pengidentifikasian, berkomunikasi dan menerapkan konsekuensi jika masalah kinerja tidak diperbaiki. Newstrom (2007: 237) mengemukakan bahwa disiplin adalah tindakan manajemen untuk menegakkan standar organisasi. Ada dua jenis, preventif dan korektif. Disiplin preventif adalah tindakan untuk mendorong pegawai untuk mengikuti standar dan penguasa sehingga pelanggaran tidak terjadi. Disiplin korektif adalah tindakan yang mengikuti pelanggaran dari aturan: itu berusaha untuk mencegah pelanggaran lebih lanjut sehingga tindakan masa mendatang akan sesuai dengan standar. Contohnya adalah peringatan atau suspensi dengan atau tanpa dibayar).

Rue dan Byars (2010:320) mengemukakan "Discipline should be view as a condition within an organization where by employees know what is expected of them interms of the organization's rules, standards and policies and what the consequences are of infractions". (disiplin harus melihat sebagai suatu kondisi dalam sebuah organisasi di mana pegawai tahu apa yang diharapkan dari mereka dalam hal aturan organisasi, standar dan kebijakan dan apa konsekuensinya dari pelanggaran). Mondy (2008:387) mengutarakan definisi bahwa "discipline is the state of employee self control and orderly conduct that indicates the extent of genuine teamwork within an organization"(disiplin adalah keadaan kontrol diri dan peraturan yang menunjukkan tingkat kerja sama tim dalam sebuah organisasi).

Berdasarkan uraian diatas maka yang dimaksud disiplin adalah kesadaran seseorang dalam melaksanakan tugas yang disertai tanggung jawab dengan landasan 
sebagai hasil proses pembelajaran untuk mengontrol diri yang mendorong ke arah perilaku yang positif agar sesuai dengan standar organisasi.

\section{METODE}

Penelitian menggunakan metode survey dengan pendekatan teknik analisis jalur. Penelitian ini dilakukan empat bulan. Penelitian dilaksanakan di wilayah Dinas Pendidikan Kabupaten Bekasi. Populasi terjangkau penelitian ini sejumlah 240 Pengawas SD. Sampel penelitian sebanyak 150 orang.

Analisa data untuk pengujian hipotesis akan dilakukan dengan menggunakan teknik analisis jalur, yaitu teknik yang diterapkan untuk menjelaskan pengaruh antara variabel-variabel penelitian. Sebelum dilaksanakan analisis jalur, uji signifikan regresi dan uji linearitas regresi sebagai prasyarat uji statistik dilakukan pengujian penormalan data dari masing-masing variabel penelitian dengan Uji-Liliefors, Statistik inferensial digunakan untuk menguji hipotesis tentang pengaruh antar variabel dengan menggunakan tekhnik analisis jalur.

\section{HASIL DAN PEMBAHASAN}

Berdasarkan hasil pengujian persyaratan analisis data dan pengujian hipotesis diperoleh hasil bahwa hipotesis yang diajukan dalam penelitian ini diterima. Hal ini berarti terdapat pengaruh langsung dan tidak langsung positif antara variabel-variabel komunikasi interpersonal, disiplin dan produktivitas.

Secara rinci hasil analisis dan pengujian hipotesis tersebut dapat dijelaskan sebagai berikut:

\section{Pengaruh Komunikasi Interpersonal terhadap Produktivitas}

Hasil analisis korelasi sederhana antara komunikasi interpersonal dengan produktvitas diperoleh koefisien korelasi sebesar 0,648 dan koefisien jalur 0,496. Dengan demikian komunikasi interpersonal dengan produktivitas memiliki pengaruh positif, artinya semakin baik komunikasi interpersonal yang dilakukan makan maka akan sebaik baik produktivitas seseorang.

Seseorang yang memiliki kemampuan berkomunikasi interpersonal yang positif akan menjadi seorang pegawai yang produktif. Hal ini sebagaimana yang dikemukakan Ivancevich (2008:361) arti pentingnya komunikasi dalam organisasi "interpersonal behavior could not exist without interpersonal communication" (Perilaku interpersonal tidak bisa aktif/produktif tanpa komunikasi interpersonal).

Hal ini juga senada dengan yang dikatakan Robbins (2005:323) bahwa ada bukti yang menunjukkan hubungan positif antara komunikasi yang efektif (yang mencakup faktor-faktor seperti kepercayaan dirasakan, akurasi dirasakan, keinginan untuk interaksi, keterbukaan manajemen puncak dan kebutuhan informasi atas) dan produktivitas pekerja). Seseorang memiliki produktivitas yang tinggi dapat dikarenakan memiliki komunikasi interpersonal yang baik Seorang manajer yang sering mengikuti pelatihan komunikasi memiliki tingkat produktivitas yang tinggi karena kemampuannya memahami dan memberikan umpan balik atas pesan/informasi yang diterimanya.

Gibson (2009:428) mengakui pentingnya perkembangan komunikasi, semakin banyak organisasi yang menerapkan program yang dirancang untuk mengukur kemampuan komunikasi manajerial dan memberikan pelatihan lanjutan untuk mengatasi kekurangannya. Manajer yang berpartisipasi dalam program tersebut ditemukan secara signifikan adanya proses ketrampilan interpersonal yang lebih tinggi 
dan dalam kemampuan pemecahan masalah mengarah ke tingkat produktivitas yang lebih tinggi dibandingkan mereka yang tidak. Oleh karena itu seorang pengawas dalam menjalankan tugasnya harus memiliki komunikasi interpersonal yang baik agar dapat berinteraksi, menerima dan penyampaikan informasi dengan sesuai yang pada akhirnya dapat mendorong produktivitasnya.

\section{Pengaruh Disiplin terhadap Produktivitas}

Hasil analisis korelasi antara disiplin dengan produktivitas diperoleh koefisien korelasi sebesar 0,550 dan koefisien jalur 0,269. Dengan demikian disiplin seseorang mempengaruhi produktivitasnya. Semakin tinggi disiplinnya maka produktivitasnya akan semakin tinggi.

Seorang pegawai yang memiliki disiplin yang baik tentunya akan lebih produktif dibandingkan yang kurang disiplin. Ketik ia mematuhi aturan dan menjalankan tugasnya maka akan mendorongnya menjadi pegawai yang memiliki produktivitas yang tinggi.

Ivancevich (1995:525) mengatakan bahwa "an employee attitude toward work is a crucial factor in achieving high productivity or performance and discipline may play an important part in this attitude" (Sikap pegawai terhadap pekerjaan merupakan faktor penting dalam produktivitas atau kinerja dan disiplin dapat memainkan peranan penting dalam sikap ini). Pegawai yang tidak disiplin dapat mengganggu produktvitas kerja organisasi karena akan mempengaruhi hasil kerjanya yang secara langsung akan berpengaruh juga terhadap terganggunya pencapaian tujuan organisasi.

Brian dalam artikelnya berjudul Succesfully implementing discipline developing A positive employeediscipline policy mengatakan bahwa menerapkan kebijakan disiplin positif dapat dicapai tanpa kehilangan kendali atas perilaku pegawai. Untuk mencapai hal ini. Perusahaan harus mengadopsi filosofi yang mencakup penyuluhan dan koreksi sebagai fokus kebijakan disiplin mereka. Banyak kebijakan berkonsentrasi pada hukuman dan benar-benar kehilangan titik dari kebijakan-mengoreksi perilaku spesifik yang mengganggu produktivitas organisasi. Seseorang yang memiliki disiplin yang tinggi akan berusaha selalu mematuhi aturan yang berlaku di dalam organisasinya pada akhirnya akan mendorong produktivitas pegawai tersebut.

Ivancevich, Konopaske (2008:512) dalam bukunya yang berjudul Human Resource Management mengemukakan sebuah aturan perilaku pegawai yang mempengaruhi produktivitas secara langsung dan tidak langsung. Perilaku yang berhubungan langsung dengan produktivitas diantaranya dalam pemanfaata waktu (waktu datang dan waktu pulang dengan tepat, pemaksimalan waktu istirahat dan kehadiran kerja yang tinggi), tidak melakukan perilaku yang dilarang (tidur pada saat bekerja, tidak meninggalkan tempat kerja tanpa izin,tidak Minum pada saat bekerja), mematuhi aturan dan perintah atasan, tidak melakukan pelanggaran secara hukum, dan tidak melakukan tindakan yang membahayakan orang lain (merokok atau membawa senjata tajam).

Lebih lanjut Ivancevich (2008:513) mengatakan bahwa "behavior rules cover many facets of on-the-job behavior. They can be categorized as concerning behavior that is directly or indirectly related to productivity" (Aturan perilaku mencakup banyak aspek perilaku dalam bekerja. Mereka dapat dikategorikan sebagai perilaku yang secara langsung atau tidak langsung berhubungan dengan produktivitas).

\section{Pengaruh Komunikasi terhadap Disiplin}


Hasil analisis korelasi sederhana antara komunikasi interpersonal dengan disiplin diperoleh koefisien korelasi sebesar 0,567 dan koefisien jalur 0,567. Dengan demikian terdapat pengaruh antara komunikasi interpersonal dengan disiplin. Hal ini mengandung bahwa bahwa semakin baik komunikasi interpersonal pengawas maka semakin baik ia dalam menerima informasi dan menjalin interaksi dengan orang lain sehingga mendorong disiplin yang lebih baik pula.

Ivancevich dan Konopaske (2008:513) dalam sebuah model dari proses menjelaskan sebuah aturan kerja akan dibuat dan dikomunikasikan kepada pegawai untuk maksud agar diikuti. Pegawai yang mampu menerima dan memahami aturan kerja pastinya akan memberikan feedback berupa ketaatan (disiplin) dibandingkan mereka yang tidak memahami. Pegawai yang tidak memahami aturan kerja maka akan diberikan tindakan disiplin.

Rue dan Byar (2008:344) mengatakan bahwa langkah pertama dalam proses disipliner adalah pembentukan persyaratan kinerja dan aturan kerja. Persyaratan kinerja biasanya dibentuk melalui proses penilaian yang dilakukan. Aturan kerja harus relevan dengan keberhasilan kinerja pekerjaan. Karena pelaksanaan aturan kerja sebagian tergantung pada kesediaan pegawai untuk menerima mereka, penelaahan berkala atas penerapan mereka adalah penting. Langkah kedua dalam proses ini adalah untuk mengkomunikasikan persyaratan kinerja dan bekerja aturan untuk pegawai. Ini biasanya ditangani melalui orientasi dan penilaian kinerja. Peraturan kerja yang berkomunikasi dalam berbagai cara.

Umumnya, seorang individu yang direkrut menerima manual yaitu menjelaskan aturan kerja dan kebijakan organisasi tersebut. Dengan departemen sumber daya manusia atau supervisor pegawai baru menjelaskan aturan ini bekerja dan kebijakan kepada pegawai baru selama orientasi. Selanjutnya, pegawai baru mungkin diperlukan untuk menandatangani dokumen yang menunjukkan mereka telah menerima dan membaca manual. Langkah terakhir dalam proses disipliner adalah penerapan tindakan korektif (disiplin) bila diperlukan. Tindakan korektif diperlukan bila kinerja pegawai di bawah ekspektasi atau bila pelanggaran aturan kerja telah terjadi.

Jadi dapat diambil kesimpulan bahwa seorang pegawai yang memiliki kemampuan menerima aturan dan memahami aturan tersebut dengan baik dan mampu memberikan feedback yang sesuai dengan aturan tersebut akan menghasilkan perilaku kerja yang efektif/disiplin.

Dikatakan pula oleh Gomez dkk (2012:481) bahwa disiplin pegawai mensyaratkan komunikasi tidak dapat diterimanya sebuah perilaku bersamaan dengan peringatan bahwa akan diikuti tindakan tertentu jika pegawai tidak mengubah perilaku. Dari paparan teori di atas dapat dikatakan bahwa seorang pegawai harus tahu apa yang diharapkan organisasi dari mereka yaitu dalam hal aturan, standar dan kebijakan organisasi. Untuk dapat memahami itu semua maka pegawai harus memiliki kemampuan berkomunikasi interpersonal yang baik yang ditandai dengan kemampuan menerima pesan/aturan yang berlaku diorganisasi dan memberikan umpan balik yang diharapkan.

\section{PENUTUP}

Kesimpulan. Berdasarkan hasil analisa dan kajian dari penelitian ini dapat disimpulkan bahwa: 
1. Komunikasi interpersonal berpengaruh langsung positif terhadap produktivitas pengawas di Dinas Pendidikan Kabupaten Bekasi.

2. Disiplin berpengaruh langsung positif produktivitas pengawas di Dinas Pendidikan Kabupaten Bekasi.

3. Komunikasi Interpersonal berpengaruh langsung positif terhadap produktivitas pengawas di Dinas Pendidikan Kabupaten Bekasi.

\section{Saran.}

1. Pemerintah seharusnya mengadakan pelatihan untuk pengembangan diri pengawas seperti diklat pengembangan komunikasi interpersonal dan memonitoring kedisiplinan pengawas serta memberikan fasilitas pendukung untuk menunjang pekerjaan sehingga memiliki produktivitas yang tinggi.

2. Pengawas hendaknya sebagai tenaga fungsional dituntut tampil profesional dalam memberikan layanan kepada kepala sekolah dan guru dengan cara terus meningkatkan kemampuan diri seperti komunikasi interpersonal dan disiplin yang baik tidak sekedar menjalankan tugasnya tetapi memberikan kontribusi yang positif terhadap sekolah binaannya sehingga mengalami peningkatan mutu pendidikan.

3. Pada penelitian selanjutnya yang sejenis diperlukan pengambilan populasi yang lebih luas, dan agar diketahui lebih banyak faktor-faktor yang mempengaruhi produktivitas pengawas. 


\section{DAFTAR RUJUKAN}

Bernadin, H. John and Joyce A. Russel. (1993). Human Resource Management. New York : McGraw Hill

Certo, Samuel C.. (2010). Supervision, Concept and Skill Building, Seventh Edition. New York: McGraw Hill

Griffin, Ricky W. (2007). Management. New York: Hougton Miffin Company

Heizer, Jay dan Barry Render. (2009). Principles of Operations Management Seventh Edition. New Jersey: Pearson Prentice Hall

Mc Shane, Steven L and Mary Ann Von Glinov. (2008). Organizational Behavior . New York: McGraw Hill

Newstrom, John W. (2007). Organizational Behavior (Human Behavior at work) (New York: Mc Graw-Hill Inc

Pearson, Judy C., Paul E. Nelson, Scott Titsworth dan Lynn Harter. (2008). Human Communication. New York: McGraw Hill

Robbins, Stephen P. dan Mary Coulter. (2009). Management. New Jersey: Pearson Prentice Hall

Rue, Leslie W. dan Lioyd L. Byars. (2010). Supervisor. New York: McGraw Hil

Vecchio, Robert P. (2006). Organizational Behavior Core Concepts, 6th second edition. USA: Thomson Corporation

Weihrich, Heinz dan Harold Koontz. (2005). Management a Global Persfective. NewYork:McGrawHill 
